\title{
The numerical simulation research of an Ultra-Light Photovoltaic Cell multilayer composite structure
}

\author{
Kangwen Sun ${ }^{1, a}$, Xinyun Zhang ${ }^{2, b}$ and Dongdong $\mathrm{Xu}^{3, \mathrm{c}}$ \\ ${ }^{1-3}$ School of Aeronautic Science and Engineering, Beijing University of Aeronautics and Astronautics, \\ Key Laboratory of Aircraft Advanced Design Technology Ministry of Industry and Information \\ Technology, Beijing 100191, China; \\ asunkw100@buaa.edu.cn, ${ }^{\mathrm{b}}$ zhangxinyunqq@sina.com, ${ }^{\mathrm{c}}$ 15202295785@163.com
}

\begin{abstract}
Keywords: The stratosphere airship; The solar cell; Honeycomb core; Three-point bending; Composite structure.
\end{abstract}

Abstract. Semi-rigid solar array is an efficient energy system on the surface of stratospheric airship for utilizing the solar energy which we believe has succeeded in providing some useful results for conceptual design. Their core consists of: To improve the flexible of rigid solar cells, a multilayer composite structure of solar cells to stratospheric airship was designed, in which rigid solar cell of encapsulation as the surface to asymmetric honeycomb core. A Glass fiber ribbon was used to improve the stiffness characteristic of the structure. It decreases the bending modulus of structural forms by $97.59 \%$ and $38.03 \%$ deflection increment. Then the different thickness of honeycomb core for the multilayered structure under pressure was analyzed by FEM( finite element method) software. Considering the quality of the whole structure, the article finally gives the conclusion of the optimal thickness of honeycomb core with more detailed descriptions. In some way, our study can provide helpful support for further engineering applications of photovoltaic cell multilayer composite structure on the surface of stratospheric airship.

\section{Introduction}

The stratosphere airship with its extensive application prospect in the field of civil and military, become the focus of the current research around the world [1,2]. Solar energy is an ideal choice to provide power for high-altitude and long-endurance airships [3]. At present, the applications of solar battery category mainly have monocrystalline silicon solar cells, polycrystalline silicon and amorphous silicon thin film solar cells. The conversion efficiency of Monocrystalline silicon solar cell is highest and its technology is also the most mature, but it belongs to the rigid solar cells. Polycrystalline silicon and amorphous silicon thin film solar cells, although has certain flexibility but the conversion efficiency is low, and Polycrystalline silicon and amorphous silicon thin film solar cell has "optical-induced degradation" [4]. Amorphous silicon thin film solar cells as the long-term use of battery about the stratosphere airship is limited because of the intense ultraviolet radiation in the stratosphere. According to the characteristics of stratospheric airship envelope (The ultraviolet intensity are at least two to three times as powerful in the stratosphere as they are at ground level), the developing trend and prospects of solar cell used in the stratosphere airship is flexible processing of rigidity solar cells to replace the traditional thin-film solar cells.

In this paper we propose an ultra-light photovoltaic cell multilayer composite structure, in which rigid solar cell of encapsulation as the surface to asymmetric honeycomb core. A Glass fiber ribbon was used to improve the stiffness characteristic of the structure. Not only to a certain degree of thermal insulation, but can decrease the stress concentration and improve the whole flexible of solar cell. Three-point bending simulation tests were carried out for both raw solar cells and cells encapsulated by honeycomb core layer in various directions. Then the different thickness of honeycomb core for the multilayered structure under pressure was analyzed by FEM( finite element method) software. Considering the quality of the whole structure, the article finally gives the conclusion of the optimal thickness of honeycomb core with more detailed descriptions. 
Physical Model. Combined with the characteristics of the stratosphere airship envelope, through the comprehensive application of surface encapsulation materials, high strength fiber material, low density flexible insulation material, a multi-layer composite structure was developed allowing application in the stratosphere airship surface.

The type selection of composite structure. Based on existing flexible insulation structures and enhancement structures, we develop a multilayer composite structure by virtue of ETFE, 22\% efficiency of monocrystalline silicon solar cells, fiberglass mesh, epoxy resin film or EVA film, and Nomex honeycomb. Solar cells with membrane surface encapsulation by EVA and ETFE film, in order to better stiffness matching with honeycomb core layer. The fiberglass has high mechanical strength and can be used as the enhancement structure. The epoxy resin or EVA film can be used as adhesive to combine each layer together. The Nomex honeycomb can effectively reduce the stress concentration of the overall structure, improve the structure's load-bearing characteristics, and also has a good capability of thermal insulation. The structure is shown as Figure 1.

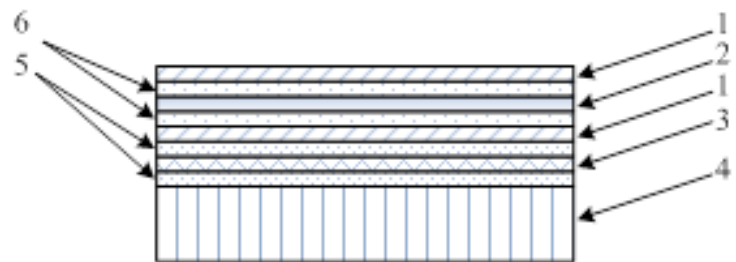

Fig.1The multilayer composite structure of solar cells

Note: 1-ETFE, 2-Silicon solar cell, 3-Fiberglass mesh, 4-Nomex honeycomb paper, 5-Epoxy resin, 6-EVA

Static comparative tests. The static comparative test aims to provide reliable mechanical performance parameters for analysis and optimization of multilayer composite structure, preliminary test and verify the reliability of asymmetric structure of honeycomb core layer. As the multilayer composite structure of solar cells underwent high deformation during the bending test, simple linear beam theory was not sufficient to calculate the stress on the cells [5]. A model was used to take the large deflections into account.

A model for calculating the large deformation under three point bending test.

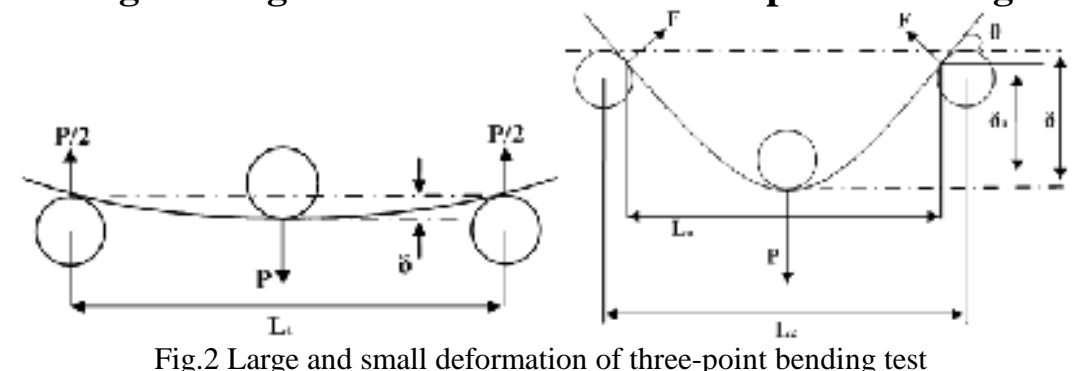

Fig.2 Large and small deformation of three-point bending test

With the classic linear beam theory, the maximum moment in the Centre of the cell is

$$
M_{\max }-\frac{P L}{1}
$$

where $\mathrm{P}$ is the load applied, and $\mathrm{L}$ the span. The maximum stress at the surface of the cell is then

$$
\sigma_{\max }=M_{I \max } \frac{l}{2}=\frac{6 M_{\operatorname{sax}}}{b t^{2}}
$$

where I is the inertia moment of the cell in flexion, B the width, and the thickness of the cell.

When the deformations are larger, the orientation of the reaction forces, the effective span and the effective displacement change. Figure 2 illustrates the difference between small displacements approximation and large displacements model.

The reaction force becomes

$$
F-\frac{P}{2 \cos (\theta)}
$$

In order to approximate the angle $\theta$, the deformed shape of the cell is assumed to follow linear 
beam theory and is expressed as

$$
y(x)-\frac{1 \delta}{L_{2}^{2}}\left(\frac{3 / 2}{2} x^{2}-x^{4}\right)
$$

where $\delta$ is the deflection at the center. The angle $\theta$ is then defined by

$$
\tan (0) \quad y\left(\frac{L_{2}}{2}\right) \frac{3 \delta}{L_{2}}
$$

The moment under the loading point can then be calculated as

$$
M_{\mathrm{m} \times \times}-\frac{P I_{n}}{4}+\Gamma \sin (0) \mathcal{E}_{n}-P_{n}+\frac{3 P \delta_{n}}{2 I_{s}}
$$

With $L_{n}=L_{2}-2 r \sin (\theta) \quad \delta_{n}=\delta-r(1-\cos (\theta))$

If the friction on the supporting pins is disregarded, the maximum stress can then be calculated with equation (1).

The comparison of test and analysis. Due the isotropic material of ETFE, the whole mechanical property of solar cell after encapsulation is isotropic. But as shown in figure 3 , honeycomb core is orthotropic material, so the overall mechanical performance of multilayer composite structure of solar cell is orthotropic.

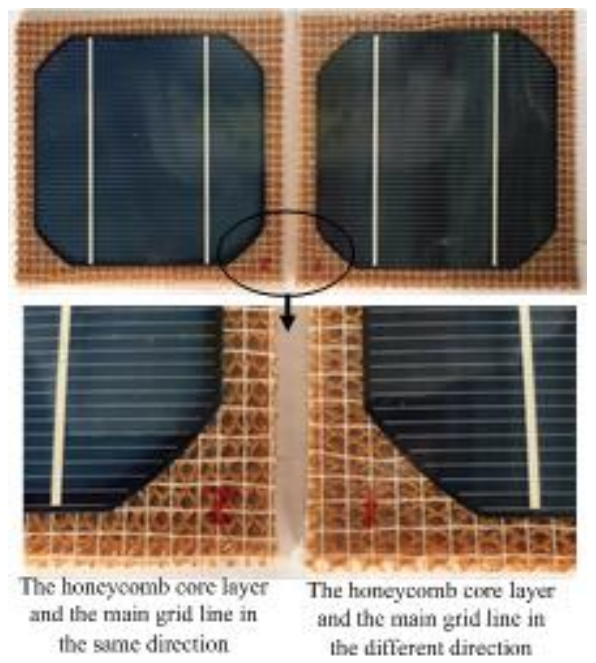

Fig. 3 The contrast test for different laminated direction of honeycomb core layer

Solar cell cannot easy break after laminated and the fracture position is hard to find. Through encapsulating and laminated, pressure can be scattered by EVA and honeycomb core layer, prevent local buckling, avoid micro cracks caused by stress concentration on the edge of the solar cell to extension.

By the results of test (see Table 1), the maximum equivalent bending stress of solar cell after encapsulation and laminated is decreases, the maximum bending strain in contrast. Its equivalent bending elastic modulus is only $2.41 \%$ after encapsulation, the deflection increased by $38.03 \%$. The flexible of the solar cell are effectively improved, which can enhance the ability of resist damage to a certain extent.

Table 1 The results of three-point bending test for Solar cells

\begin{tabular}{ccccc}
\hline $\begin{array}{c}\text { The types of Solar } \\
\text { cell }\end{array}$ & $\begin{array}{c}\text { The maximum equivalent } \\
\text { bending stress /MPa }\end{array}$ & $\begin{array}{c}\text { Maximum } \\
\text { strain } / \%\end{array}$ & $\begin{array}{c}\text { Deflectio } \\
\mathrm{n} / \mathrm{mm}\end{array}$ & $\begin{array}{c}\text { The equivalent elastic } \\
\text { modulus /GPa }\end{array}$ \\
\hline $\begin{array}{c}\text { EVA encapsulation } \\
\text { Various directions of } \\
\text { Honeycomb core }\end{array}$ & 27.45 & 0.79 & 6.1 & 3.48 \\
The same direction & 1.35 & 1.33 & 6.52 & 0.101 \\
of Honeycomb core & 1.22 & 1.46 & 8.42 & 0.084 \\
\hline
\end{tabular}

The simulation of multilayer composite structure. According to the sealing property of multilayer composite structure, stress and strain of solar cells cannot be measured. AS the different intensity of 
the composite every layer, Test cannot determine if the damage under the layers of material. So it is practically important to carry on the study on the whole structure of 3D FEM model.

Finite element analysis model. Three-point bending selected three kinds of different thickness of honeycomb core layer to simulate like $2 \mathrm{~mm}, 5 \mathrm{~mm}$ and $8 \mathrm{~mm}$. The geometrical model, contact property, boundary condition and load step are modeled and settled in ABAQUS/CAE and the mechanical properties of ETFE, EVA and others are given and listed in Table 2[6-8].

Table 2 The mechanical properties

\begin{tabular}{cccccc}
\hline $\begin{array}{c}\text { The type of mechanical } \\
\text { properties }\end{array}$ & ETFE & EVA & $\begin{array}{c}\text { The solar } \\
\text { cell }\end{array}$ & $\begin{array}{c}\text { Fiberglass } \\
\text { mesh }\end{array}$ & $\begin{array}{c}\text { Epoxy } \\
\text { resin film }\end{array}$ \\
\hline E (GPa) & 0.837 & 0.655 & 52.12 & 11.4 & 1.1 \\
Poisson's ratio $\mu$ & 0.42 & 0.3 & 0.3 & 0.28 & 0.38 \\
Thickness $(\mathrm{mm})$ & 0.05 & 0.2 & 0.29 & 0.14 & 0.2 \\
\hline
\end{tabular}

The meshing scheme of the model is shown in Fig. 4. Eight-node reduced integration element with hourglass control (C3D8R) and four node bilinear rigid quadrilateral element (R3D4) are implemented for mesh discretization of the 3D braided composite specimen and rollers. or mesh discretization of the 3D braided composite specimen and rollers.

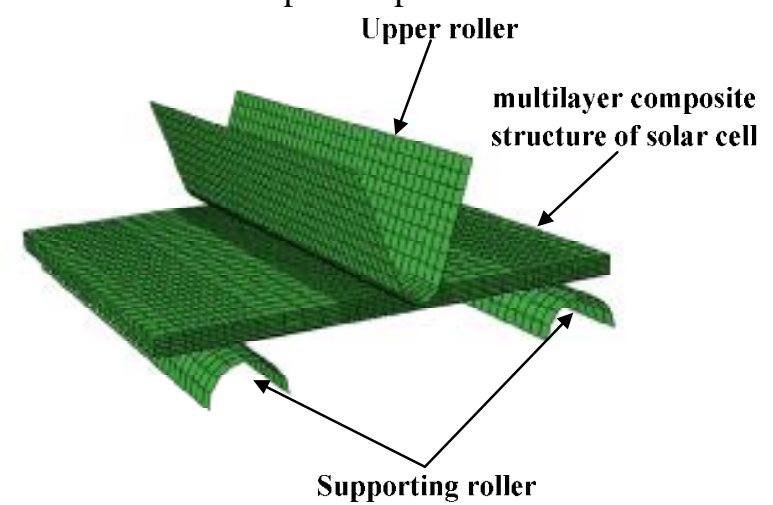

Fig.4 The finite element mesh model of the bending test about multilayer composite structure of solar cells

The equivalent mechanical performance of honeycomb core layer. Based on multilayer composite structure model, with a view to the discrete heterogeneity of the honeycomb material, to simplify the analysis, the honeycomb material is equivalent to orthotropic material. This places a lot of emphasis on the selection of the equivalent model.

The equivalent calculation of elastic modulus $E_{1}$ and $E_{2}$

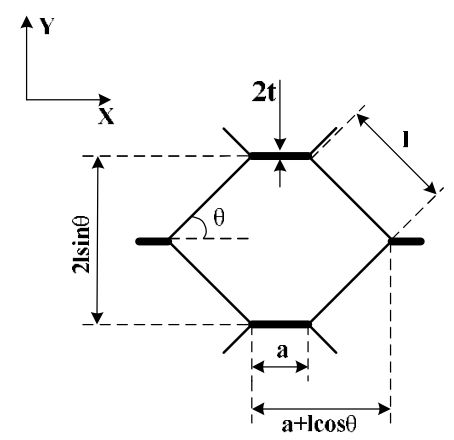

(a)

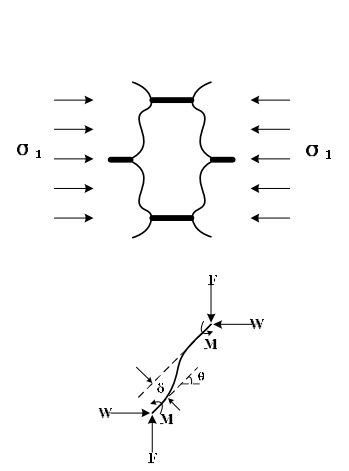

(b)

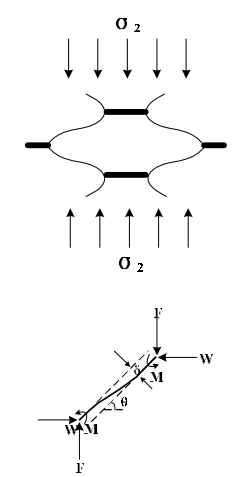

(c)

Fig.5 (a) unloaded; (b) bending load in the X-direction; (c) bending load in the Y-direction

Loading in the $\mathrm{X}$ and $\mathrm{Y}$ direction as shown in Fig.5, each wall is modelled as a beam of thickness $\mathrm{t}$ or $2 \mathrm{t}$, depth $\mathrm{b}$. By the condition of equilibrium, analysis of length 1 of hole wall $F=0 \mathrm{~W}=\sigma_{\mathrm{l}} l b \sin (\theta)$, so

The wall deflects by

$$
M=\frac{W l \sin (\theta)}{2}
$$




$$
\delta=\frac{W l^{3} \sin \theta}{12 E_{s} I}
$$

Of this, a component $\delta$ is parallel to the $\mathrm{X}$-axis, giving a strain

$$
\varepsilon_{1}=\frac{\delta \sin \theta}{a+l \cos \theta}=\frac{\sigma_{1} l^{4} \sin ^{3} \theta}{t^{3} E_{s}(a+l \cos \theta)}
$$

From which the Young modulus parallel to the $\mathrm{X}$-axis is $E_{1}=\sigma_{1} / \varepsilon_{1}$, so

$$
E_{1}=E_{s}\left(\frac{t}{l}\right)^{3} \frac{a / l+\cos \theta}{\sin ^{3} \theta}
$$

Similarly, the Young modulus parallel to the X-axis is $E_{2}=\sigma_{2} / \varepsilon_{2}$, so

$$
E_{2}=E_{s}\left(\frac{t}{l}\right)^{3} \frac{\sin \theta}{(a / l+\cos \theta) \cos ^{2} \theta}
$$

The calculation of shear modulus $\mathbf{G}_{\mathbf{1}}$ The calculation of the shear modulus is illustrated by figure 6. By symmetry, there is no relative motion of the points $\mathrm{A}, \mathrm{B}$ and $\mathrm{C}$. The shearing deflexion of the structure is entirely due to the bending of beam $\mathrm{BD}$ and its rotation about the point $\mathrm{B}$. The forces are shown in the figure. Summing moments at $\mathrm{B}$, we find the moment applied to the members $\mathrm{AB}$ and $\mathrm{BC}$ is $M=F a / 4$
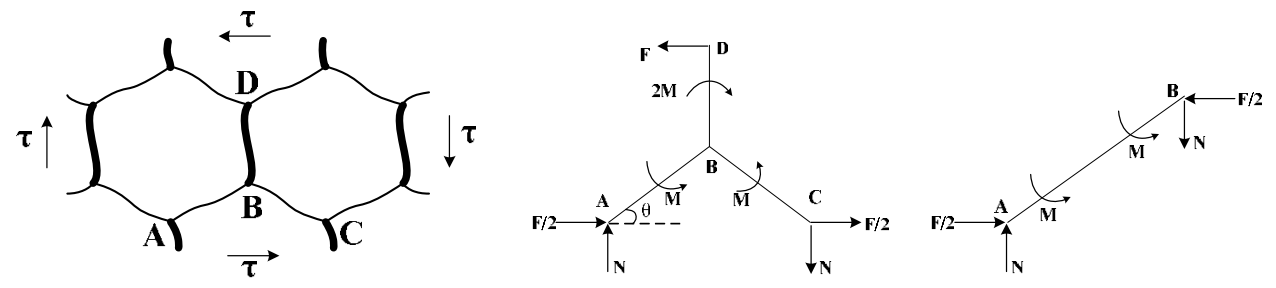

Fig.6 Cell deformation under shear stress

Literature References All the joints rotate through an angle ${ }^{\varphi}$.Then, since there is no deflexion of $\mathrm{B}$ with respect to $\mathrm{A}$, we have

$$
\varphi=\frac{M_{A} l}{3 E_{s} I_{1}}-\frac{M_{B} l}{6 E_{s} I_{1}}=\frac{F a l}{24 E_{s} I_{1}}
$$

By assuming that shear deformation consists of the rotation of the cell wall BD around point $\mathrm{B}$ and bending formation of BD. So $\mu_{B D}=\varphi a+\delta_{B D}$, and:

$$
\delta_{B D}=F \frac{a^{3}}{3 E I_{2}}-2 M \frac{a^{2}}{2 E I_{2}}
$$

Value for $\delta_{B D}$ is as follows:

$$
\mu_{B D}=\frac{F a^{3}}{12 E I_{2}}+\frac{F a^{2} l}{24 E I_{1}}=\frac{F a^{2}}{24 E I_{1}}\left(\frac{a}{4}+l\right)
$$

The shear strain:

$$
\gamma_{x y}=\frac{\mu_{B D}}{a+l \sin \theta}
$$

The shear stress:

$$
\tau=\frac{F}{2 b l \cos \theta}
$$

So the shear modulus $G_{1}$ is given:

$$
G_{1}=\frac{\tau}{\gamma_{x y}}=E_{s}\left(\frac{t}{l}\right)^{3} \frac{(a / l+\sin \theta)}{(a / l)^{2} \cos \theta(a / 4 l+1)}
$$

Based on the above theory, considering the actual size of honeycomb core layer after layer pressure, set up the equivalent mechanical properties of honeycomb core layer as shown in table 3 . 
Table 3. The equivalent mechanical properties of honeycomb core layer

\begin{tabular}{cc|cc}
\hline Type & Values & Type & Values \\
\hline Double hole wall $(\mathrm{a})$ & $1.5 \mathrm{~mm}$ & Single hole wall $(\mathrm{l})$ & $2 \mathrm{~mm}$ \\
Honeycomb angle $(\theta)$ & $55^{\circ}$ & Nomex paperboard thickness $(\mathrm{t})$ & $0.13 \mathrm{~mm}$ \\
Elastic modulus of Nomex paperboard $\left(\mathrm{E}_{\mathrm{s}}\right)$ & $1780 \mathrm{M} \mathrm{Pa}$ & Shear modulus of Nomex paperboard $\left(\mathrm{G}_{\mathrm{s}}\right)$ & $623 \mathrm{M} \mathrm{Pa}$ \\
Elastic modulus of honeycomb core layer $\left(\mathrm{E}_{1}\right)$ & $1.18 \mathrm{MPa}$ & Elastic modulus of honeycomb core layer $\left(\mathrm{E}_{2}\right)$ & $0.92 \mathrm{M} \mathrm{Pa}$ \\
Shear modulus of honeycomb core layer $\left(\mathrm{G}_{1}\right)$ & $2.01 \mathrm{M} \mathrm{Pa}$ & & \\
\hline
\end{tabular}

The mechanics performance optimization of multilayer composite structure The predicted load-deflection curves of honeycomb core layer in multilayer composite structure with different thickness under three point bending are given in Fig. 7.

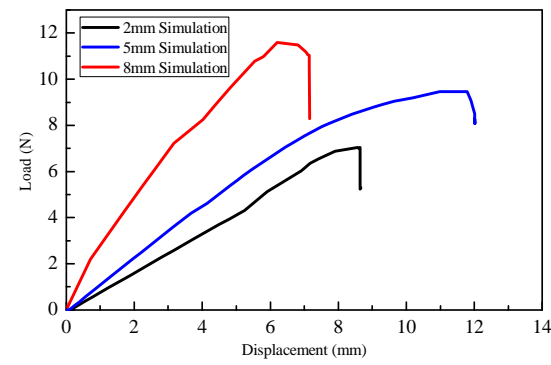

Fig.7 The load-deflection curves of honeycomb core layer with different thickness

Different thickness of honeycomb core layer effects on bending properties It is observed from Fig. 13 that the load-deflection curves show a similar changing tendency of the applied load and can be divided into three stages: the initial linear elastic stage, the nonlinear stage with the minor damage evolution and the curve descending stage with a sudden drop of the load. The linear stage exhibited the linear elastic relationship between the load and deflection and no damages occurred in the specimens. The initial damages started on the solar cell layer but multilayer structure disperses pressure and reduces stress concentration, to prevent the crack extension and meanwhile the load might still have a corresponding increase. The sharply drop of the load was caused by the damages occurred on the solar cell layer, as shown in Fig. 8: Subsequently the multilayer composite structure lost their loading capacity.

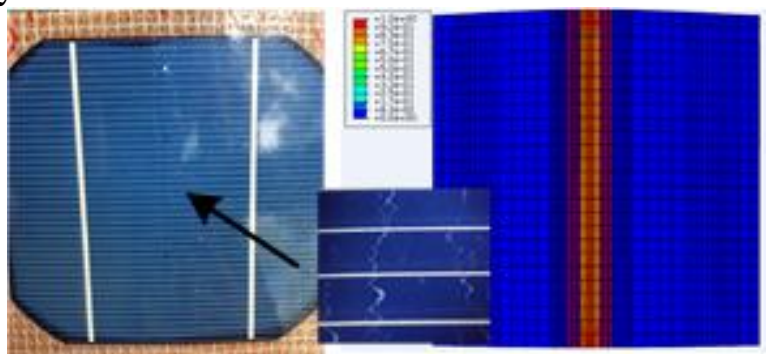

Fig.8 Damage distribution of honeycomb core specimen with $5 \mathrm{~mm}$ thickness

Through the comparison between the different thicknesses of honeycomb core layer, the load-deflection curves of the initial slope and ultimate load increases with the decrease of thickness of honeycomb core layer. But according to the asymmetry of the structure and the local buckling of honeycomb core layer under large deformation, cause to the nonlinear relation of load-dependent deformation [9-10].

This paper describes the conception which is deflection weight ratio; it will use to analyze different thickness of honeycomb core layer to improve the deflection of multilayer composite structure considering the structure weight as shown in Table 4. 
The more deflection weight ratio, the more ascension of multilayer composite structure. We can see from Table 4, to improve the deflection of structure, $5 \mathrm{~mm}$ honeycomb core layer is the optimal choice compared with $2 \mathrm{~mm}$ and $8 \mathrm{~mm}$.

Table 4. Deflection weight ratio with different thickness

\begin{tabular}{cccc}
\hline $\begin{array}{c}\text { Thickness of honeycomb } \\
\text { core layer } / \mathrm{mm}\end{array}$ & $\begin{array}{c}\text { The increase of } \\
\text { deflection } / \mathrm{mm}\end{array}$ & $\begin{array}{c}\text { The increase of } \\
\text { structure weight } / \mathrm{g}\end{array}$ & $\begin{array}{c}\text { Deflection weight } \\
\text { ratio } /\left(\mathrm{mm} \cdot \mathrm{g}^{-1}\right)\end{array}$ \\
\hline 2 & 5.6 & 6.1 & 0.92 \\
5 & 9.4 & 7.97 & 1.18 \\
8 & 4.5 & 9.4 & 0.48 \\
\hline
\end{tabular}

\section{Conclusions}

This paper developed a multilayer composite structure according to the characteristics of stratospheric airship hull. In order to improve the flexible of the solar cell, we studied the mechanical properties of solar cell after encapsulation and laminated in different cell direction using three-point bending test. Then the different thickness of honeycomb core for the multilayered structure under pressure was analyzed by FEM software. Considering the quality of the whole structure, the article finally gives the conclusion of the optimal thickness of honeycomb core with more detailed descriptions.

(1) As the multilayer composite structure of solar cells underwent high deformation during the bending test, simple linear beam theory was not sufficient to calculate the stress on the cells. The analytical results show that the orientation of the reaction forces, the effective span and the effective displacement will all change in high deformation, the impact on the test should not be neglected.

(2) The maximum equivalent bending stress of solar cell after encapsulation and laminated is decreases, the maximum bending strain in contrast. Its equivalent bending elastic modulus is only $2.41 \%$ after encapsulation, the deflection increased by $38.03 \%$. The flexible of the solar cell are effectively improved, which can enhance the ability of resist damage to a certain extent.

(3) Through the comparison between the different thicknesses of honeycomb core layer, this paper describes the conception which is deflection weight ratio; it will use to analyze different thickness of honeycomb core layer to improve the deflection of multilayer composite structure considering the structure weight and $5 \mathrm{~mm}$ honeycomb core layer is the optimal choice compared with $2 \mathrm{~mm}$ and $8 \mathrm{~mm}$.

\section{Acknowledgements}

This work was supported by the National Natural Science Foundation of China under Grant No. 51307004 and Basic research funds of BeiHang University.

\section{References}

[1] Benedek .L .Solar Energy and the Aeronautics Industry, National Aeronautics and Space Administration [R]. Washington, DC.Nov1985.74p .Report: NAS 1 .15: 77957; NASA TM-77957, 1985.

[2] C.Roberts, M.Vaughan, W.J.Bowman. Development of a Solar Powered Micro Air Vehicle[R].Reston AIAA 2002.

[3] Wang,Q.Chen,J.Fu,G.,Duan,D.,Zhao,H. A methodology for optimization design and analysis of stratosphere airship. The Aeronautical Journal. 2009. 
[4] Sun K W, Yang Q Z,et al. Thermal Characteristics of Multilayer Insulation Materials for Flexible Thin-Film Solar Cell Array of Stratospheric Airship [J]. Advances in Materials Science and Engineering,2014,76(5):300-308.

[5] Rion J,Geiser A,Leterrier Y,Mnson J-AE. Ultra-light Asymmetric Photovoltaic Sandwich Structures. Journal of Composites . 2009

[6] B. L. Lee,J. W. Song,J. E. Ward. Failure of Spectra Polyethylene Fiber-Reinforced Composites under Ballistic Impact Loading. Journal of Composite Materials . 1994

[7] GIBSON L J,ASHBY M F,SCHAJER G S. The me-chanics of two-dimension cellular materials. Proc R Soc A

[8] $\mathrm{Hu} \mathrm{L}$, Liu Z,Wang Y,et al. Experiments and progressive damage analyses of three-dimensional full five-directional braided composites under three-point bending [J]. Polymer Composites,2015,10(5):231-248

[9] Hitchen SA,J Kemp R M, The effect of stacking-sequence on impact damage in a carbon fiber/epoxy composite[J].Composites, 1995,26:207-214.

[10] Zhu HX,Mills NJ. The in-plane non-linear compression of regular honeycombs. International Journal of Solids and Structures . 2000 